\title{
Los feminismos de Spinoza: corporalidad y renaturalización
}

\section{Spinoza's Feminisms: Corporeality and Renaturalization}

ISABEL BALZA*

\begin{abstract}
Resumen: La corporalidad es pensada en el feminismo contemporáneo como el ámbito que permite articular un nuevo modo de la comunidad política, invirtiendo así el paradigma liberal al poner el acento sobre la materialidad y carnalidad de los sujetos, aquello considerado «impersonal» por la tradición liberal. En este trabajo analizo las condiciones éticas y ontológicas necesarias para enunciar tal modo del orden político. Ello a partir de las propuestas de autoras como Moira Gatens, Elizabeth Grosz, Rosi Braidotti o Hasana Sharp, quienes han llevado a cabo una interpretación de la filosofía de Spinoza en clave feminista.

Palabras clave: Spinoza, Cuerpos, Impersonal, Biopolítica feminista, Materialismo, Renaturalización.
\end{abstract}

\begin{abstract}
In contemporary feminism, corporeality is thought of as the field that allows to articulate a new mode of political community, thus reversing the liberal paradigm by placing the emphasis on materiality and carnality of the subjects, that are considered «impersonal» by the liberal tradition. In this paper I analyze the necessary ethical and ontological conditions to formulate this political order. All this starting from the proposals of authors such as Moira Gatens, Elizabeth Grosz, Rosi Braidotti or Hasana Sharp, who have carried out an interpretation of Spinoza's philosophy in a feminist key.
\end{abstract}

Key words: Spinoza, Bodies, Impersonal, Feminist Biopolitics, Materialism, Renaturalization.

«Mas busca la vida ante todo su cuerpo, el despliegue del cuerpo que ya alcanzó, el cuerpo indispensable. Y busca otro cuerpo desconocido.» María Zambrano, «Los Bienaventurados», 17

\section{Una (bio)política feminista desde Spinoza}

En sus últimos trabajos, Judith Butler ${ }^{1}$ explora la posibilidad de un proyecto normativo crítico con el que defiende la tradición liberal y aboga por una comunidad donde sea posi-

Fecha de recepción: 29/05/2014. Fecha de aceptación: 30/07/2014.

* Profesora Titular de Filosofía Moral en la Universidad de Jaén. Forma parte del Grupo de Investigación de la Junta de Andalucía SEJ 348:«Biopolíticas». Sus actuales líneas de investigación son la filosofía feminista contemporánea y la biopolítica. Entre sus publicaciones recientes: Balza, Isabel (2013), «Hacia un feminismo monstruoso: sobre cuerpo político y sujeto vulnerable», en Suárez Briones (ed.), Las lesbianas (no) somos mujeres. En torno a Monique Wittig, Barcelona, Icaria, pp. 85-115. Balza, Isabel (2013), «Tras los monstruos de la biopolítica», Dilemata. Revista Internacional de Éticas Aplicadas, 12, pp. 27-46. ibalza@ujaen.es

1 Todos ellos posteriores a los atentados del 11S, como son: Vida precaria. El poder del duelo y la violencia (2006), Marcos de guerra. Las vidas lloradas (2010) y Violencia de Estado, guerra, resistencia. Por una nueva política de la izquierda (2011). 
ble el duelo y la responsabilidad hacia cualquier otro. La ontología que Butler se propone construir piensa la corporalidad como un ámbito que permite articular un nuevo modo de la comunidad política, invirtiendo así el paradigma liberal al poner el acento sobre la materialidad y carnalidad de los sujetos, aquello considerado «impersonal» por la tradición liberal.

Desde posturas republicanas -o republicanistas-, Butler pretende articular una suerte de biopolítica positiva que dé cuenta de las vidas de todos los sujetos. Frente a proyectos de biopolíticas negativas o destructivas, en el sentido en el que las enuncia Esposito (2007), creo que Butler se propone pensar y atrapar conceptualmente aquello de la vida que se escapa al marco liberal de pensamiento. Para ello, nos presenta un panorama de los dispositivos de la biopolítica negativa, que ya había trazado antes en sus Cuerpos que importan, al analizar los mecanismos de exclusión referidos a la sexuación y las sexualidades. Ahora se fija en los marcos raciales y étnicos que juegan en las prácticas de borramiento y rechazo de lo humano. Y entiende, al igual que Agamben y Esposito, que éstos marcan dos esferas separadas de la vida, una vida humana - bíos - y otra vida como mera condición biológica -zoé- (Butler, 2006, 98).

Esposito insiste en que una versión liberal de la ontología desecha un ámbito del ser humano a lo informe, para acabar siendo destruido. También Butler va a incidir en esta cuestión, y aunque reconozca la necesidad de una perspectiva liberal sobre la autonomía del sujeto y la propiedad del cuerpo, encuentra que ello no es suficiente. Está claro que Butler no quiere renunciar a las reivindicaciones del derecho a la autodeterminación y la integridad corporal, que suponen una perspectiva liberal de la autonomía del sujeto, pues ello ha permitido que las luchas de las feministas, de gays y lesbianas o de los transexuales e intersexuales hayan sido posibles. No obstante, encuentra que es urgente articular y defender algún otro tipo de proyecto normativo.

Y para ello va a fijarse en todo aquello, dice, que nos arranca de nosotros mismos y nos conduce a un «afuera», un lugar que Butler quiere explorar para construir a partir de ahí una nueva forma de comunidad política. Como vamos a ver, si la ontología liberal da cuenta del bios, de la forma de vida que en esta versión política coincide con la definición legal de lo que somos, Butler cree urgente recuperar para la palabra y el derecho lo que queda como una sombra informe (zoé) en el esquema liberal, ese ámbito de la vida que nombra como deseo y vulnerabilidad física.

Lo que nos arranca de nosotros mismos es la corporalidad y materialidad que nos constituye, y Butler concibe esa carnalidad humana como potencia que trasciende al propio sujeto, aquello que lo libra de su soledad inmanente como ser individual. Porque ahora es la corporalidad -y no ya el alma o el espíritu- la que dota de trascendencia al ser humano. Butler pone el acento sobre la materialidad y carnalidad de los sujetos, insistiendo en que es el cuerpo y no ya el alma o la razón lo que de modo privilegiado permite vincularnos unos a otros. De ahí que proclame «una insurrección a nivel ontológico» (Butler, 2006, 59).

El cuerpo nos trasciende porque la vulnerabilidad física de nuestros seres carnales es la condición universal de los sujetos, por lo que la tarea es la de inventar qué modo de la política puede expresar esta vulnerabilidad. Esta precariedad es la nota común de la vida humana, e incluso de la vida como tal, en tanto que nos liga también con los animales no humanos (Butler, 2010, 30). Pero, además, la vulnerabilidad es rasgo primero de los sujetos, siendo una condición del despojo inicial y del desamparo. Por ello nos precede y, al ser cua- 
lidad principal de la vida, es la condición de todo estar. Y lo que va a ser muy importante a la hora de articular una comunidad: precede también a toda forma de contrato político, puesto que no se elige estar en la precariedad (Butler, 2011, 34).

Este proyecto de biopolítica afirmativa que Butler se propone planea sobre aquello que el pensamiento liberal había desechado, sobre la mera vida primera, sobre la propia materia informe que nos constituye. Y Butler denomina «vida precaria» a ese lugar de la vulnerabilidad inicial ${ }^{2}$.

Pero, para dar sentido a lo Butler propone, habrá que indagar en las condiciones éticas y ontológicas necesarias para articular tal modo de orden político. Quiero plantear aquí que la política de la vida precaria que Butler persigue sólo podrá ser articulada si la remitimos a un concepto de vida y de corporalidad que recoja la tradición spinoziana. Ya Butler insinúa ${ }^{3}$ que deberíamos volver a repensar las categorías spinozianas para poder enunciar nuevos modos de la política que asuman la vulnerabilidad corporal. Mas si atendemos a las críticas que ha recibido el esquema butleriano de pensamiento, parece difícil conjugarlo con esa impronta spinoziana.

Autoras como Moira Gatens, Elizabeth Grosz, Susan James, Genevieve Lloyd, Rosi Braidotti, Beth Lord o Hasana Sharp, entre otras, han llevado a cabo una interpretación de la filosofía spinoziana en clave feminista, señalando la necesidad de considerar la corporalidad desde los planteamientos de Spinoza. Por otra parte, autoras que se enmarcan en lo que se denomina «Feminismo material», como son Stacy Alaimo, Claire Colebrook, Karen Barad o Vicki Kirby, entre otras (Alaimo y Hekman, 2008), también van a indagar en las raíces materialistas del feminismo. Muchas de ellas se enfrentan al denominado feminismo de género (o feminismo de la igualdad), y criticarán las posiciones teóricas de Butler, como veremos.

¿A qué nos referimos cuando enunciamos una biopolítica feminista? Con biopolítica feminista me refiero a un modo de entender la ligazón entre la vida y su norma, o un modo de articular la política que dé cuenta de aquellos aspectos de la vida que el feminismo ha reivindicado siempre, como son la materialidad de los cuerpos y la vulnerabilidad de los sujetos. Una biopolítica feminista abordará aquello considerado impersonal por la ontología liberal, aquello desechado por no considerarse propio del ámbito del sujeto, aquello que, más bien, roza lo animal o que nos emparenta con lo animal.

Porque ha sido el feminismo quien se ha ocupado de esos lugares precarios, de esos topos vulnerables. Es el feminismo quien ha atendido a la corporalidad y vulnerabilidad subjetivas. Quizá sea el momento de una alianza entre el feminismo como teoría crítica, la ontología spinoziana y la mejor tradición republicana ante los distintos ataques que sufren los derechos y los cuerpos de las mujeres. Ante las distintas cruzadas moralistas que sustraen nuestra libertad y nos condenan a la miseria. Es esta alianza entre el feminismo y Spinoza lo que me interesa explorar.

2 Aunque Butler va a insistir en que la vulnerabilidad no afecta por igual a todos los sujetos, sino que distingue la noción de «precariedad» (ontológica), en la que todos estamos, de la de «precaridad» (política o social) que afecta de modo diferencial a los sujetos.

3 «Mientras que la mayoría de las posturas derivadas de los relatos spinozistas de la persistencia corporal recalcan el deseo productivo del cuerpo, ¿hemos encontrado ya nosotros un relato spinozista de la vulnerabilidad corporal o considerado sus implicaciones políticas?» (Butler, 2010, 52). 


\section{Porque la Ciudad es de las Damas}

Cuando releemos a Spinoza y lo interpretamos en clave feminista, lo primero que nos sorprende es la exclusión de las mujeres de la política democrática, tal y como leemos en los dos últimos parágrafos de su Tratado Político: «He dicho, además, que, aparte de estar sometidos a las leyes del Estado, sean en lo demás autónomos, a fin de excluir a las mujeres y a los siervos, que están bajo la potestad de los varones y de los señores.» (Spinoza, 1986a, 222). La razón principal que Spinoza despliega para expulsar a las mujeres de la polis es la desigualdad natural entre los dos sexos, no teniendo las mujeres «por naturaleza, un derecho igual al de los hombres, sino que, por necesidad, son inferiores a ellos» (Spinoza, 1986a, 223). Entiende el filósofo que del hecho histórico de que las mujeres no hayan participado en la vida política se sigue la necesidad de que ello deba ser así por naturaleza.

No obstante, creo, como defiende Beth Lord $(2011,1087)$, que la privación de la libertad de las mujeres y su exclusión de la participación política por parte de Spinoza no es debida a su naturaleza esencial, sino a sus circunstancias sociales e históricas. Según esta interpretación, Spinoza erraría a la hora de llevar a cabo el diagnóstico de las razones por las que las mujeres de hecho han estado expulsadas del ámbito de la vida política, habiendo tomado como esencial o natural aquello que sólo ha sido social e histórico. Su error se cifraría en haber asumido como naturaleza lo que es historia. Pero lo importante es que para Spinoza no hay razón que a priori obligue a prescindir de las mujeres en la política democrática, si argumentamos que su subordinación ha estado fundamentada en las leyes y no en la naturaleza humana ${ }^{4}$, lo que desde una perspectiva feminista está bien demostrado.

Para Moira Gatens la exclusión de las mujeres de la participación política por parte de Spinoza es una «cicatriz» en el cuerpo de su obra, que deforma su propia filosofía (Gatens, 1996, 134). Esta cicatriz se expresa como una contradicción, ya que Spinoza radica en la propia naturaleza de las mujeres su falta de independencia y la limitación de su autonomía a la autoridad de los hombres. Y como recuerda Gatens, este tipo de argumentario es extraño al corpus de Spinoza, ya que él mismo carga en el Tratado teológico-político contra los estereotipos raciales o nacionales, al afirmar que la naturaleza forma individuos, no pueblos, y que las disposiciones y prejuicios que distinguen tipos de pueblos son el resultado de las leyes y costumbres específicas, no de la naturaleza. Lo curioso es que Spinoza defiende la exclusión de las mujeres basándose no en las cualidades o predisposiciones de las propias mujeres, sino en las predisposiciones de los hombres: es porque los hombres son sensibles a los encantos femeninos que hay que expulsarlas de la vida política, ya que son la causa de los celos que provocan en los hombres, lo que dificulta el buen discurrir democrático ${ }^{5}$. Este argumento no sería de ningún modo admisible en el

4 «Mas quizá pregunte alguno si acaso las mujeres están bajo la potestad de los hombres por naturaleza o por ley. Ya que, si ese hecho sólo se fundara en una ley, ninguna razón nos forzaría a excluirlas del gobierno» (Spinoza, 1986a, 222).

5 «Y, si consideramos, además, los afectos humanos, a saber, que los hombres casi siempre aman a las mujeres por el solo afecto sexual y que aprecian su talento y sabiduría en la misma medida en que ellas son hermosas; y que, además, los hombres soportan a duras penas que las mujeres, que ellos aman, favorezcan de algún modo a otros, y hechos por el estilo, veremos sin dificultad que no puede acontecer, sin gran prejuicio para la paz, que los hombres y las mujeres gobiernen por igual» (Spinoza, 1986a, 224). 
contexto de la filosofía política spinoziana, ya que Spinoza defiende todo tipo de pasiones para los hombres, lo que incluiría la lujuria y los celos que las mujeres (supuestamente) les provocan.

Gatens afirmará que es la limitación histórica de Spinoza la que le impide ver las implicaciones de su propio pensamiento, y por ello defiende el desdén ante estas afirmaciones excluyentes, abogando por disfrutar y aprovechar las partes de su filosofía que sirvan a los propósitos feministas.

Pero, en todo caso, no es éste el tema principal que quiero comentar. Porque más allá de las interpretaciones que Spinoza haga del hecho de la subordinación de las mujeres a lo largo de la historia, me importan las consecuencias que de su ontología podemos extraer a la hora de articular una biopolítica feminista. En este sentido, uno de los puntos en los que me apoyaré en este trabajo es la interpretación de Hasana Sharp de la ontología spinoziana y su propuesta de una renaturalización de la política.

\section{Un feminismo material o renaturalizado}

Desde Moira Gatens, pasando por Rosi Braidotti y llegando hasta Hasana Sharp, las autoras que han interpretado a Spinoza en clave feminista coinciden en señalar algunos puntos que son esenciales a la hora de pensar las implicaciones para las prácticas políticas feministas de la filosofía spinoziana.

Así, tanto Gatens, James y Lloyd, como Vacarezza, Larrauri, Braidotti, Grosz y Sharp, van a insistir en señalar el nuevo esquema de pensamiento que ofrece la filosofía spinoziana frente al modelo cartesiano. En primer lugar, frente al binarismo cartesiano ahora tenemos un monismo que disgrega los dualismos como mente-cuerpo, razón-pasión, naturaleza-cultura. La ruptura de los dualismos ha sido fundamental para el feminismo y para su modo de pensar el sexo/género, cuestión principal, por ejemplo, en el pensamiento de Butler.

Otro punto que se reivindica para el feminismo desde la filosofía de Spinoza es el papel que la corporalidad juega en su pensamiento, lo que permite también al feminismo pensar las consecuencias que la materialidad tiene en el análisis de las opresiones. La idea de que el cuerpo siempre se halla en un contexto social, en tanto que se compone con otros cuerpos, ayuda al feminismo a examinar la opresión de las mujeres desde esta perspectiva, ya que la libertad para Spinoza es una cuestión colectiva y no individual, y ello, como afirman Gatens y Lloyd (James, Lloyd y Gatens, 2000, 48), acerca a Spinoza a posturas republicanas, alejándolo del Liberalismo.

Vacarezza insiste en que esta visión no dicotómica ni mecánica de los cuerpos obliga a contextualizar el modo en que éstos se componen y descomponen, porque la materialidad de los cuerpos implica preguntar por sus condiciones históricas, por las categorías que los piensan y categorizan. Ello hace que las relaciones de poder en que se componen los cuerpos deban ser analizadas. Pero no se trata de modelos de cuerpos formados mecánicamente, «la lectura de Spinoza más bien invita a pensar en cuerpos singulares, productivos y creativos que no pueden ser mecánicamente producidos ni definitivamente conocidos» (Vacarezza, 2010,6). Es en el siguiente apartado donde insistiré en esta cuestión. 
Además, la composición de los cuerpos implica reconocer tanto su potencia como su vulnerabilidad $^{6}$. Y lo que aquí me interesa destacar: la composición de los cuerpos hará referencia a su trascendencia material, al mismo tiempo que a su descentramiento subjetivo. Que un cuerpo vaya más allá de sí mismo -como hemos visto que Butler nos propone- significa que es la corporalidad la que dota de trascendencia al sujeto. Esto sólo puede ser concebido bajo el prisma de la filosofía de Spinoza. Porque la propuesta de Butler se entenderá si la enmarcamos en un pensamiento no humanista como el que defiende Hasana Sharp, refiriéndose al feminismo antihumanista de Grosz y a su principal fuente de referencia, Spinoza. En la última parte de este trabajo, que he llamado «lo impersonal también es político», examinaré el modo en que se conjuga la inmanencia spinoziana con la trascendencia subjetiva (material) que aquí se reivindica.

Lo que ahora quiero analizar son las consecuencias teóricas y políticas que para el feminismo tiene el monismo spinoziano.

Frente a la ontología dualista de la tradición filosófica europea, el pensamiento de Spinoza proporciona las herramientas conceptuales necesarias para desarticular los binarismos que el feminismo critica por ser fundamentadores de la opresión de las mujeres y sustentadores de la ideología patriarcal. En efecto, el esquema monista de Spinoza desarma los pares mente/cuerpo, razón/pasión o naturaleza/cultura, entre otros. Al defender -y demostrar- que el alma y el cuerpo son modos de expresión de una única sustancia, abre el camino al pensamiento para imaginar interpretaciones alternativas de la vida y la política de los sujetos. Es por ello que autoras vinculadas con lo que se ha venido en llamar «feminismo de la diferencia», como Gatens, Braidotti o Grosz, conectan con esta tradición monista y reivindican a Spinoza para el feminismo.

Lo que estas teóricas feministas van a subrayar es que la ontología spinoziana permite una conceptualización de las diferencias que nunca las dicotomiza o polariza ${ }^{7}$. En efecto, para Spinoza cada individuo es una de las formas en que la naturaleza se singulariza, porque no hay una regla fundamental de la que se sigan las demás, ya que «cada cosa natural tiene por naturaleza tanto derecho como poder para existir y para actuar» (Spinoza, 1986a, 85). De ahí que se puedan pensar las diferencias de modo no oposicional ni jerárquico, lo que precisamente es lo que el feminismo persigue.

Pero, además, Spinoza es atractivo para el feminismo de la diferencia porque permite conceptualizar la diferencia sexual y, por lo tanto, la diferencia de ser «mujer». Recordemos que para este feminismo propio de la tradición europea, el papel que juega la diferencia sexual en la construcción de la subjetividad humana es prioritario, frente al papel secundario que le otorga a la sexuación y a la encarnación humana lo que Braidotti engloba bajo el nombre de feminismo postestructuralista estadounidense, donde se hallarían De Lauretis, Scott o la misma Butler (Braidotti, 2005, 52). Braidotti insistirá en cómo Spinoza afirma

6 «Dada su capacidad de afectar y de ser afectado por otros cuerpos, cada cuerpo resulta el locus de una existencia expuesta y dirigida hacia otros, de exposición y necesidad de otros, lo cual configura la existencia corporal como un espacio paradójico, de vulnerabilidad y potencia» (Vacarezza, 2010, 5).

7 Así, Gatens: «Spinozist philosophy is capable of suggesting an account of the body and its relation to social life, politics and ethics that does not depend on the dualisms that have dominated traditional modern philosophy. Yet neither is it a philosophy which neutralizes difference. Rather it allows a conceptualization of difference which is neither dichotomized nor polarized» (Gatens, 1996, 56). 
la multiplicidad de diferencias posibles, frente al binarismo hombre/mujer, presentando la diferencia como positividad de las diferencias, y no como diferencias jerarquizadas o negativizadas (Braidotti, 2005, 94). Braidotti tiene claro que es desde Spinoza desde donde el feminismo podrá superar el dualismo y reconectar la vida con el pensamiento. Es por eso que reivindica una alianza entre el feminismo y el pensamiento nómada, proyecto en el que lleva trabajando los últimos años.

En este sentido, también desde el denominado «Feminismo material» (Alaimo y Hekman, 2008) se critica al feminismo postestructuralista su mantenimiento de las dicotomías. Este feminismo defiende una reconfiguración de la naturaleza y se halla muy próximo a las propuestas del feminismo de la diferencia ${ }^{8}$. Desde planteamientos monistas, el feminismo material aboga por un «giro material» en la teoría feminista, pues se trata de tomarse en serio la materia, donde la naturaleza es contemplada como fuerza y agente activo, más que como construcción social pasiva. Lo que se critica es el llamado «giro lingüístico» del feminismo, cuyo ejemplo paradigmático sería el que Butler representa. El punto central de la crítica es que aunque el feminismo postestructuralista estadounidense (o postmoderno, según lo denominan) defienda rechazar toda dicotomía, siga manteniendo en sus premisas teóricas la dicotomía lenguaje/realidad (Alaimo y Hekman, 2008, 2). Y una de sus consecuencias será la falta de materia, sobre todo de materialidad corporal, que por ejemplo Butler presenta en sus propuestas. Creo que para este giro material del feminismo, tan cercano a las propuestas del feminismo que podemos llamar spinoziano, la ontología de Spinoza es la más adecuada para desarrollar sus tesis.

Como vemos las críticas a Butler, y al feminismo postestructuralista estadounidense, son comunes tanto al «feminismo material», como a Braidotti ${ }^{9}$, Gatens y Sharp. De este modo, se sigue manteniendo la distancia entre -al menos- dos modos del feminismo, y manteniendo así la dicotomía en el seno de la propia teoría feminista. Con respecto a ello, Moira Gatens propone que, precisamente, una ontología spinoziana permitiría abandonar el impasse de la teoría feminista contemporánea cifrada en afirmar, por una parte, una igualdad mental esencial y, por otra, una diferencia corporal esencial (Gatens, 1996, 57). Gatens entiende que criticar la dualidad propia de la historia patriarcal implica también desmarcarse de la división dual del feminismo (Gatens, 2002, 143), heredero del marco de referencia que acepta el dualismo cuerpo/mente y el de naturaleza/cultura. En definitiva, esta división en el seno de la teoría feminista se correspondería a dos respuestas que priorizan uno de los dos polos de la división, la mente o el cuerpo, y la naturaleza o la cultura.

En este sentido interpreto también la propuesta de Hasana Sharp de renaturalizar la política (y la filosofía) (Sharp, 2011). La filosofía spinoziana nos permite imaginar un feminismo renaturalizado, que no se corresponde en ningún caso con la interpretación que del feminismo de la diferencia suele ser común, en tanto que defensor de esencias femeninas incrustadas. Ahora se trata de construir un feminismo que desde luego sabe qué son las inter-

8 Éstas son algunas de las autoras que aparecen en el volumen editado por Alaimo y Hekman: Elizabeth Grosz, Claire Colebrook, Karen Barad, Donna J. Haraway, Vicki Kirby, Elizabeth A. Wilson y Susan Bordo. Pero, además, se declaran en diálogo con el trabajo de, entre otras, Luce Irigaray, Rosi Braidotti, Susan Wendell, Val Plumwood, Lynda Birke, Nina Lykke y Gloria Anzaldúa (Alaimo y Hekman, 2008, 10).

9 Braidotti encuadra a Butler fuera del postestructuralismo de la diferencia sexual, en tanto que no reconoce el poder transformador de lo femenino para subvertir el falogocentrismo (Braidotti, 2005, 65). 
pretaciones culturales sedimentadas sobre los $\operatorname{sexos}^{10}$, pero que tampoco por ello renuncia a tener presentes las diferencias que nuestra materia y corporalidad nos depara. Se trata de renaturalizar lo femenino, tratando de recuperar el significante «mujer» y de no renunciar a él, retornando, como dice Braidotti, sus versátiles complejidades.

Un feminismo material o renaturalizado trasciende la división dual de los feminismos, porque ya no distinguimos entre la mente y el cuerpo, o la naturaleza y la cultura. El alma es ya expresión de nuestros cuerpos, y éstos deben ser pensados en todas sus diferencias ${ }^{11}$.

\section{La ética encarnada}

Uno de los puntos que siempre se destacan de la ontología de Spinoza es que ésta es una filosofía del cuerpo. Deleuze afirmará que propone un nuevo modelo a los filósofos, el del cuerpo (Deleuze, 2001, 27); Larrauri calificará su pensamiento como «la primera filosofía del cuerpo» ${ }^{12}$; para Braidotti, Spinoza forma parte de la cara oculta de la filosofía occidental, de esa contramemoria filosófica que ella quiere recuperar para trazar la dimensión somática de la filosofía, para llevar a cabo su proyecto de pensar ese materialismo encarnado o inscrito: el materialismo de la carne (Braidotti, 2005, 18). El paralelismo entre el alma y el cuerpo que Spinoza defiende, junto con la inmanencia radical que predica, hace que su filosofía sea el lugar adecuado y necesario para poder recorrer lo que Braidotti llamará «la senda de la carne». Porque con Spinoza ya sólo tenemos una sustancia que se expresa en los modos del alma y del cuerpo, por lo que la materia ocupa un lugar paralelo al del pensamiento. Ya no son el alma, la mente o el pensamiento lugares privilegiados o prioritarios en el sistema filosófico; ahora la materia y la corporalidad deben ser escuchadas y pensadas de la misma manera. Y para ello deberemos tener en cuenta el aspecto encarnado de la subjetividad.

Bien, pero ¿qué significa la condición corporal de la subjetividad? ¿Acaso ello hace referencia a un nuevo modo de naturalismo o biologismo? Como afirma Braidotti, cuando pensamos qué significa la encarnación humana no podemos reducirla a una categoría natural o biológica, porque el concepto de «cuerpo» debe ser entendido como una interacción compleja de fuerzas sociales y simbólicas, como una superficie de intensidades (Braidotti, 2005, 37). En este mismo sentido, Gatens defiende que la encarnación («embodiment») en Spinoza hace referencia al contexto afectivo de ese cuerpo, y no sólo al cuerpo individual o aislado (Gatens, 1996, 131). Ser cuerpo no significa ser solo carne, en el sentido de materia

10 Así entiende Braidotti el término «esencia»: «Si «esencia» significa la sedimentación histórica de productos discursivos multiestratificados, ese cúmulo de definiciones, exigencias y expectativas culturalmente codificadas sobre las mujeres, o sobre la identidad femenina - ese repertorio de ficciones reguladoras tatuadas en nuestras pieles-, entonces, sería falso negar no sólo que esta esencia exista sino, también, que es poderosamente operativa» (Braidotti, 2005, 61).

11 En ello se cifra para Montserrat Galcerán el desafío del feminismo contemporáneo: «Dejemos pues atrás las anteriores dicotomías: ni el sexo es lo natural, ni el género es lo cultural. Ambos están tecnológicamente construidos por medio de tecnologías sociales y bio-médicas. Éste es el desafío del feminismo contemporáneo: construir un devenir-mujer no «identitario» o encorsetado en la diferencia, ni «igual» a lo masculino, sino autónomo y atento a nuestros deseos y experiencias» (Galcerán, 2009, 163).

12 Este texto de Maite Larrauri es uno de los pocos del ámbito hispano donde se plantean las repercusiones que para el feminismo tiene la ontología spinoziana: «un pensamiento capaz de abordar el cuerpo, la materia en su especificidad. La filosofía de Spinoza es la primera filosofía moderna materialista, la primera filosofía del cuerpo» (Larrauri, 1989, 11). 
inerte, sino ser materia viva que recoge la memoria de los encuentros con otros cuerpos, las inscripciones en la carne de los afectos. Porque, como Spinoza sentenció, el alma es la representación del cuerpo, pero ambos son una única sustancia. La dimensión somática de la subjetividad debe ser pensada a partir del conatus de Spinoza en términos vitalistas, «como materia viva anhelando devenir y continuar deviniendo» (Braidotti, 2005, 95).

Pero la filosofía no se distingue ciertamente por haberse ocupado de la corporalidad. Muy al contrario, un repaso a la historia del pensamiento occidental pone de relieve la falta de atención que, salvo algunas excepciones, a la materia y al cuerpo se le ha prestado; excepciones que, como Spinoza, el feminismo trata de recuperar. Ya Elizabeth Grosz detectaba somatofobia en el origen mismo de la filosofía occidental, ese miedo original que percibe el cuerpo como un principio de interferencia y un peligro para los intereses de la razón (Grosz, 1994, 5); y Braidotti entiende que la negación de lo material o de la facticidad corpórea es elemento constitutivo de la metafísica occidental (Braidotti, 2005, 80). No es casual que sea el feminismo quien principalmente haya denunciado este rechazo de lo corporal. Porque no es que la filosofía no haya pensado el cuerpo, sino que, como afirma Gatens, las concepciones filosóficas tradicionales de la corporalidad son contraproducentes para la construcción de una concepción autónoma del cuerpo de las mujeres y la posibilidad de su participación activa en la vida ético-política (Gatens, 1996, 49).

Lo que sobre todo se denuncia es que el cuerpo político moderno -construido a partir del siglo XVII- se representa como un producto de la sola razón, donde el cuerpo y la pasión estarían ausentes. Este cuerpo político es un cuerpo artificial reducido a racionalidad, y en tanto que cuerpo inmaterial estaría desprovisto de sexuación. Como es bien sabido, el feminismo ha denunciado esta supuesta neutralidad y universalidad del cuerpo político moderno. Y lo que Gatens señala es que incluso algunas feministas, como Firestone o Beauvoir, han aceptado una concepción de la corporalidad como parte de la cruda naturaleza, apartándola así de la cultura y de la historia. Pues precisamente, al compartir la visión moderna que entiende el cuerpo como un fenómeno ahistórico, estarían legitimando la visión de las mujeres como parte del «estado de naturaleza», ausente, por tanto, del «cuerpo político» (Gatens, 1996, 51).

Porque la cuestión aquí es determinar cómo las mujeres pueden llegar a ser «cuerpos políticos». Está claro que el siglo XVII legitima la exclusión de las mujeres de la esfera de lo racional y de la vida política. Pero es evidente que ese supuesto cuerpo asexuado y neutral es un cuerpo masculino, concebido desde y para los hombres. Por ello Gatens entiende que necesitamos un espacio teórico no dominado por el isomorfismo entre cuerpos masculinos y cuerpos políticos (Gatens, 1996, 55). Y es desde Spinoza desde donde cree que tal lugar del pensamiento puede ser concebido.

Si la política tradicional toma el cuerpo y sus pasiones como ya virtualmente dados, en tanto que los asume como una naturaleza biológica a priori, Gatens entiende que una política construida desde la ontología spinoziana puede dar conocimiento de la especificidad cultural e histórica de los cuerpos, en tanto que adopta un punto de vista en el que la naturaleza no es mecánica sino dinámica y productiva (Gatens, 1996, 58). Ya que el cuerpo es ahora el fundamento de la acción humana, y no ya parte de una naturaleza pasiva. No sabemos lo que puede un cuerpo porque el cuerpo es un proceso, y los límites de la encarnación dependen de su contexto. 
En este sentido, retomo la pregunta final del trabajo de Maite Larrauri, cuando se cuestiona si debemos continuar pensando una ética de corte universal o si bien es posible fundamentar un sujeto ético femenino a partir de la ontopolítica spinoziana ${ }^{13}$. Para Gatens está claro que esta política corporizada se acompaña de una ética encarnada a su vez, una ética que no puede pretenderse universal, pues el supuesto sujeto universal que representaba ha sido ya desplazado. El cuerpo político que representa un supuesto cuerpo común sólo admite unos específicos tipos de persona como miembros activos, y en ese esquema las mujeres y otros muchos grupos quedan excluidos de la esfera civil, en tanto que sus diferencias deben ser subsumidas en el cuerpo político común, concebido a partir del hombre blanco heteronormativo. Gatens apuesta por la política spinoziana porque aquí se pueden concebir las diferencias, siempre irreductibles y vinculadas al aspecto concreto de las vidas de los individuos ${ }^{14}$.

Esta ética encarnada que se postula es una ética de las diferencias ${ }^{15} \mathrm{o}$, en el sentido en que se reclama desde el «feminismo material», es una «ética material», en tanto en cuanto es una ética que compara las consecuencias reales materiales de las posiciones morales y, así, traza conclusiones de estas comparaciones (Alaimo y Hekman, 2008, 7). Y como afirma Spinoza, las consecuencias que conducen al florecimiento o alegría de lo humano son válidas y buenas frente a aquéllas que denigran (y descomponen) a los individuos con la tristeza.

Creo que la distinción que ofrece Deleuze entre «ética» y «moral» con respecto a la Ética de Spinoza apunta al meollo de la cuestión. Deleuze afirma que la Ética es «una tipología de los modos inmanentes de existencia», que «reemplaza la Moral, que refiere la existencia a valores transcendentes.» (Deleuze, 2001, 34). Y efectivamente, la inmanencia radical que Spinoza postula para la naturaleza coloca en un mismo plano ontológico a todos sus individuos - sean animales o humanos- y, por ello, como afirma Deleuze, la Ética es una etología. Esta igualdad radical hace posible el desarrollo de las capacidades de cualesquiera cuerpos, almas, individuos; porque un cuerpo «puede ser cualquier cosa,

13 Larrauri se pregunta si el sujeto ético de Spinoza es un sujeto ético masculino. Ella lo contrapone al modelo griego de sujeto universal y ético (siguiendo a Foucault). Y frente a ese modelo griego de dominio de sí, como modelo rígido, contrapone el modelo de Spinoza como un modelo plástico y flexible. En el modelo griego las mujeres no tienen cabida, por quedar fuera de los límites establecidos de sujeto. Así, si el modelo de límite-contorno griego diseñó una sociedad masculina, Larrauri insinúa (o apuesta) que el modelo de Spinoza, al ser plástico y tener en cuenta lo sensible, permite el advenimiento de las mujeres como sujetos ciudadanos: «si la concepción del límite-contorno diseñó una sociedad tan exclusivamente masculina, ¿es posible que una ética que toma, como modelo, el desarrollo de la naturaleza y los cuerpos para concebir el límite como algo dinámico, sirva para las mujeres? ¿Puede la filosofía de Spinoza enseñarnos a fundamentar un sujeto ético femenino? Creo haber hecho todo lo posible para inclinar la balanza hacia una respuesta afirmativa» (Larrauri, 1989, 28).

14 Para Braidotti es en este esquema de pensamiento donde el feminismo contemporáneo debe desarrollarse, en tanto que respeta las diferencias y, por ello, las diferencias de ser de las mujeres: «El materialismo encarnado de la diferencia sexual es la afirmación de la importancia de una multiplicidad que puede producir sentido otorgando el reconocimiento simbólico al modo de ser de las mujeres» (Braidotti, 2005, 81).

15 Creo que otras propuestas que quieren expresar las diferencias irreductibles de las subjetividades, como la de Margrit Shildrick, pueden ser encuadradas en este esquema spinoziano. En este caso, utilizando la categoría de «monstruo», en tanto que sujeto no normativo, se propone una «ética de la vulnerabilidad»: «What I propose is a new form of ethics that answers more fully to the multiplicity of embodied difference, and as such, it is precisely my intention to undo the singular category of the monster...I turn away from such normative ethics to embrace instead the ambiguity and unpredictability of an openness towards the monstrous other. It is a move that acknowledges both vulnerability to the other, and the vulnerability of the self» (Shildrick, 2002, 3). 
un animal, un cuerpo sonoro, un alma o una idea, un corpus lingüístico, un cuerpo social, una colectividad» (Deleuze, 2001, 155); y ahí estamos incluidas las mujeres, por supuesto.

\section{Lo impersonal también es político}

La inmanencia radical que postula Spinoza se acompaña de una idea de la trascendencia subjetiva que radica en su materialidad. Con Spinoza ya no buscamos una dimensión suplementaria de lo dado, ni hay designios divinos, ni se trata de averiguar cuál es la evolución de la naturaleza, ni el desarrollo de los sujetos. Ahora los cuerpos se componen unos con otros, no hay ya sujeto, sino más bien estados afectivos y fuerzas que se encuentran (Deleuze, 2001, 156). Ahora la única trascendencia posible es la de los cuerpos que se encuentran con otros cuerpos, la materia componiéndose. En este sentido, el antihumanismo spinoziano, al no privilegiar de ningún modo a los humanos en el conjunto de la naturaleza, hace que pasemos de un esquema dominado por el antropocentrismo a un igualitarismo biocentrado, en una visión, en palabras de Braidotti, «profundamente inscrita del sujeto encarnado» (Braidotti, 2005, 85).

También los feminismos que estamos analizando, como el de Braidotti, Sharp, Gatens o Grosz, comparten esta visión antihumanista propia del spinozismo y destacan, a su vez, la necesidad para el feminismo de una política animada por las pasiones, de una política dominada por la alegría ${ }^{16}$. Este antihumanismo spinoziano obliga ahora a pensar qué aspectos subjetivos habían quedado relegados para la política en un esquema humanista o liberal y, en este sentido, Hasana Sharp ofrece una interpretación muy sugerente de Spinoza, y defiende la posibilidad de recuperar para la política y lo público todo aquello perteneciente al ámbito de la materia o de lo corporal, lo silenciado o prediscursivo, todo lo que podemos nombrar como «impersonal».

Hasana Sharp (2009 y 2011) hace una lectura de un artículo de Elizabeth Grosz (2002) en el que critica la política del reconocimiento, frente a la que defiende una política de la imperceptibilidad y/o de lo impersonal. La crítica de Grosz de la política del reconocimiento se cifra en que, por una parte, cualquier política humanista está centrada en una dialéctica entre el mismo y el otro; y, por otra, critica la política del reconocimiento porque su humanismo siempre es masculino. Sharp, por su parte, sostiene que es a través de la filosofía de Spinoza que puede articularse tal política de lo impersonal que Grosz reclama, y defiende que es Spinoza quien ofrece recursos teóricos para poder articular una política de la corporalidad, la proximidad, el poder y la conexión, que incluye a toda la naturaleza, algo que el feminismo, sostiene Sharp, debe explorar. Lo que se defiende para el feminismo contemporáneo es una vuelta a la multiplicidad y a la desunión de las fuerzas naturales y corporales, a lo no discursivo, al terreno de los afectos, de las acciones no representables ${ }^{17}$. Y Sharp señala que para ello es necesaria una teoría no humanista de la agencia y el deseo (Sharp, 2009, 93).

16 La alegría spinoziana que es consecuencia de la inmanencia que predica, en palabras de Toni Negri: «Spinoza instala esa dimensión alegre en la metafísica, en el momento preciso en que -o tal vez porque- anula esta última y la devuelve a la superficie del mundo» (Negri, 2000, 36).

17 Así, podemos añadir a Sharp a esa estirpe de filósofas que han sido encuadradas por Nina Lykke $(2010,131)$ dentro del feminismo postconstruccionista, cuyo nexo común es su relación con las facticidades prediscursivas de los cuerpos y las relaciones transcorporales. Braidotti, Grosz, Barad o Alaimo, son algunas de las autoras que cita Lykke en su trabajo. 
Se trata entonces de pensar un feminismo no humanista, y para ello se reivindica la ontología de Spinoza. Sharp critica toda forma de humanismo y antropocentrismo, y cifra el antihumanismo de Spinoza en su defensa de que las leyes y poderes que determinan la existencia humana no son diferentes de aquéllas que determinan y expresan la naturaleza como un todo. Recordemos el final del prefacio de la III parte de la Ética, donde dice: «...y consideraré los actos y apetitos humanos como si fuese cuestión de líneas, superficies o cuerpos» (Spinoza, 1984, 182).

En este sentido, Sharp critica el humanismo de Butler, que ella supone en textos como Deshaciendo el género. Pero creo que en los últimos libros de Butler, como son Marcos de guerra. Las vidas lloradas y Vida precaria. El poder del duelo y la violencia, se puede percibir un cierto antihumanismo que la acerca a la postura de Sharp y de Spinoza. Recordemos que Butler reivindica el hermanamiento con los animales no humanos, y la primacía que la materialidad de los cuerpos y su trascendencia tiene para una nueva política, como vimos al comienzo de este trabajo. Esta nueva política que Butler busca no es -no puede ser- humanista, ya que se centra en las fuerzas frente a los sujetos.

En este sentido, Sharp considera que tras la desnaturalización del sexo y el género, fundamental para el feminismo, es necesaria una renaturalización. Esta renaturalización implica concebir a los sujetos como instantes del infinito poder de la naturaleza, frente al reconocimiento social que la intersubjetividad ofrece dentro de un esquema propio de la política del reconocimiento. La práctica política que se sigue de la renaturalización de lo humano no niega aspectos presentes en el reconocimiento, pero va más allá. Ahora se incluye la colaboración con los otros, pero teniendo en cuenta que estos otros acogen más seres que los humanos. Este es el aspecto ecologista de la filosofía spinoziana, que la enmarca en una biopolítica afirmativa.

La política de lo impersonal o de lo imperceptible se cifra pues en ser una crítica del humanismo, que incluye un proyecto de renaturalización y una consideración de las fuerzas materiales que son indiferentes a las conceptualizaciones humanas, aunque las incluyan. En este sentido, Spinoza ofrece una de las mayores críticas de la trascendencia humana. Pero esta política de lo impersonal no trataría de desplazar los esfuerzos por el reconocimiento intersubjetivo, sino de abrir nuevas vías de pensamiento para la efectiva política, considerando a los sujetos en términos de fuerzas y energías.

¿Qué implicaciones tiene una política de lo impersonal para el feminismo? Frente a la vieja consigna feminista de que «lo personal es político», ahora se trata de articular el modo en que lo impersonal también sea político. Así, un feminismo de raíces republicanas abogará por la defensa de aquello que un feminismo de corte liberal no contempla; a saber: la trascendencia que los cuerpos presentan, los deseos en que se fundamentan. Ello no implica que, por ejemplo, la práctica feminista de la concienciación no tenga lugar en esta política de lo impersonal (en tanto que desprivilegia la conciencia y la intersubjetividad). Tal práctica ha sido fundamental para el feminismo, a ello va unida su principal máxima de «lo personal es político». Pero aquí estamos tratando de pensar si lo impersonal es político también, no de negar que lo personal lo sea. Se trata de abrir nuevas vías de pensamiento y de acción política para el feminismo.

Porque, como sugiere Sharp, la práctica feminista de la concienciación debe ser abordada desde una perspectiva impersonal. No se trata ya de reconocer lo que somos, sino lo que deseamos. Una política de lo impersonal toma su punto de partida del deseo de aumentar el placer 
y el poder en el encuentro con otros cuerpos. Es una política afectiva que privilegia activar las relaciones, donde sea que se den, más allá de los humanos o las instituciones (Sharp, 2009, 101).

Sharp aboga por articular, a partir de Spinoza, una política feminista de lo impersonal que tenga en cuenta todo ser y fuerza que ayude en la construcción de «una insurgencia alegre contra el patriarcado, la misantropía y el odio hacia una misma» (Sharp, 2009, 101). Una política animada por un deseo de afectos alegres y de placeres corporales. Spinoza se presenta como remedio a los afectos tristes que genera el mal reconocimiento, al ofrecer recursos para el desarrollo de una política de la corporalidad, la proximidad y la conexión más allá y excediendo a lo humano. Y es sólo a partir de tal política feminista de lo impersonal fundamentada en Spinoza como podrá articularse la política de la vida precaria que Butler está buscando.

\section{Referencias bibliográficas}

Alaimo, Stacy y Hekman, Susan (eds.) (2008), Material Feminisms, Bloomington e Indianapolis, Indiana University Press.

Braidotti, Rosi (2005), Metamorfosis. Hacia una teoría materialista del devenir, Madrid, Akal.

Butler, Judith (2011), Violencia de Estado, guerra, resistencia. Por una nueva política de la izquierda, Barcelona, Katz.

- (2010), Marcos de guerra. Las vidas lloradas, Madrid, Paidós.

- (2006), Vida precaria. El poder del duelo y la violencia, Buenos Aires, Paidós.

- (2002), Cuerpos que importan. Sobre los límites materiales y discursivos del «sexo», Buenos Aires, Paidós.

Deleuze, Gilles (2001), Spinoza: Filosofía práctica, Barcelona, Tusquets.

Esposito, Roberto (2009), Tercera persona. Política de la vida y filosofía de lo impersonal, Buenos Aires, Amorrortu.

- (2007), Bíos. Biopolítica y filosofía, Buenos Aires, Amorrortu.

Galcerán, Montserrat (2009), Deseo (y) libertad. Una investigación sobre los presupuestos de la acción colectiva, Madrid, Traficantes de Sueños.

Gatens, Moira (ed.) (2009), Feminist Interpretations of Benedict Spinoza, Pennsylvania, The Pennsylvania State University Press.

Gatens, Moira (2002), «El poder, los cuerpos y la diferencia», en: M. Barret y A. Phillips (eds.): Desestabilizar la teoría. Debates feministas contemporáneos, México, Paidós, pp. 133-150.

- (2000), «Feminism as «Password»: Re-thinking the «Possible» with Spinoza and Deleuze», Hypatia, vol. 15, no 2, pp. 59-75.

- (1996), Imaginary Bodies. Ethics, Power and Corporeality, Londres y Nueva York, Routledge.

Gatens, Moira y Lloyd, Genevieve (1999), Collective Imaginings. Spinoza, Past and Present, London y New York, Routledge.

Grosz, Elizabeth (2002), «A politics of imperceptibility: A response to 'Anti-racism, multiculturalism and the ethics of identification'», Philosophy \& Social Criticism, vol. 28, $\mathrm{n}^{\mathrm{o}} 4$, pp. 463-472. 
- (1994), Volatile Bodies. Toward a Corporeal Feminism, Bloomington e Indianapolis, Indiana University Press.

James, Susan, Lloyd, Genevieve y Gatens, Moira (2000), «The Power of Spinoza: Feminist Conjunctions», Hypatia, vol. 15, n 2, pp. 40-58.

Larrauri, Maite (1989), Spinoza y las mujeres, Valencia, Fundación Instituto Shakespeare / Instituto de Cine y RTV.

Lord, Beth (2011), «'Disempowered by Nature': Spinoza on The Political Capabilities of Women», British Journal for the History of Philosophy, vol. 19, nº 6, pp. 1085-1106.

Lykke, Nina (2010), «The Timeliness of Post-Constructionism», NORA-Nordic Journal of Feminist and Gender Research, vol. 18, n 2, pp. 131-136.

Negri, Antonio (2000), Spinoza subversivo, Madrid, Akal.

Sharp, Hasana (2011), Spinoza and the Politics of Renaturalization, Chicago y Londres, The University of Chicago Press.

- (2009), «The Impersonal Is Political: Spinoza and a Feminist Politics of Imperceptibility», Hypatia, vol. 24, no 4, pp. 84-103.

Shildrick, Margrit (2002), Embodying the Monster. Encounters with the Vulnerable Self, London, Sage Publications.

Spinoza, Baruch (1986a), Tratado político, Madrid, Alianza Editorial.

- (1986b), Tratado teológico-político, Madrid, Alianza Editorial.

- (1984), Ética demostrada según el orden geométrico, Madrid, Editora Nacional.

Vacarezza, Nayla (2010), «Aportes de Spinoza para reflexionar acerca de la vida corporal del género, las mujeres y el feminismo», A Parte Rei. Revista de Filosofía, no 71, pp. 1-10. 